\title{
The Lived Experience of Residents in an Emerging Master-Planned Community
}

\author{
Laurie Buys $^{1, * \mathbb{C}}$, Cameron Newton ${ }^{2} \mathbb{D}$ and Nicole Walker ${ }^{1}(\mathbb{D}$ \\ 1 Health and Behavioural Sciences Faculty, University of Queensland, St Lucia, QLD 4072, Australia; \\ n.walker4@uq.edu.au \\ 2 Faculty of Business and Law, Queensland University of Technology, Brisbane, QLD 4000, Australia; \\ cj.newton@qut.edu.au \\ * Correspondence: 1.buys@uq.edu.au
}

Citation: Buys, L.; Newton, C.; Walker, N. The Lived Experience of Residents in an Emerging Master-Planned Community. Sustainability 2021, 13, 12158. https://doi.org/10.3390/su132112158

Academic Editor: Vida Maliene

Received: 30 September 2021

Accepted: 2 November 2021

Published: 4 November 2021

Publisher's Note: MDPI stays neutral with regard to jurisdictional claims in published maps and institutional affiliations.

Copyright: (c) 2021 by the authors. Licensee MDPI, Basel, Switzerland. This article is an open access article distributed under the terms and conditions of the Creative Commons Attribution (CC BY) license (https:// creativecommons.org/licenses/by/ $4.0 /)$.

\begin{abstract}
Master-planned communities around the world are developed and purposefully planned to address housing sustainability and community connectivity; they often have a distinctive look, and appeal to a particular customer base desiring a strong, utopian-esque community. However, the lived experience of new residents joining master-planned communities has not been explored. This paper examines the lived experience of new residents within an emerging Australian master-planned estate, and reports on the first two stages of a longitudinal study focusing on the results of an online forum. This unique study presents real-life findings on a culturally diverse community. The findings reveal how the purposeful development of community identity in the early stages of the MPCommunity has not led to satisfactory levels of social infrastructure or social connectedness for the pioneering residents. The physical and social environment, as interpreted by residents against the developers' imagined vision and marketing testimonies, has not been entirely satisfactory. Infrastructure issuessuch as transport, and access to daily activities such as shopping, work, and school-were points of frustration and dissatisfaction. The findings provide insight into the challenges and opportunities for residents in a developing MPC, and further our understanding of the specific factors that inform us as to how social infrastructure can best encourage and support connection within existing and future MPC developments.
\end{abstract}

Keywords: master-planned estate; community; community identity; social connectedness; social infrastructure: physical infrastructure; housing developments; longitudinal study

\section{Introduction}

Creating residential communities that provide housing and accommodation along with an engaging environment that facilitates community connections has been a priority for many cities and communities. There have been a variety of approaches to addressing this challenge, with recent development focusing on master-planned communities (MPCs) [1]. MPCs are capital-intensive forms of master-planned estates (MPEs), purposefully designed to encourage the development of community identity and connectivity [2] Given recent global events, including COVID-19, providing insight into how MPCs are experienced in the initial stages of their development, by people from diverse backgrounds, is important to delivering sustainable communities [3]. This study explores the lived experiences-specifically social connectedness - in an attempt to gain a better understanding of the issues faced by a group of pioneer residents in relation to their everyday community lives together in the early stages of MPC development; it does this by first examining the notion of MPCs, and the characteristics that are designed to influence the development of community within them, and then investigates an incipient MPCommunity (the label for the case study MPC) in Australia. 


\subsection{Community}

The term "community" is part of common parlance, and is entrenched in urban planning and design, yet it lacks a fixed meaning, either stated or contested. It must be acknowledged that communities are not static entities, but are dynamic, and self-organise over time. Structures of interaction between residents change both as an outcome of changes in local interactions, and/or in response to external social challenges, such as COVID-19 [4].

Community has positive connotations as an adjective elevating nouns such as "development", "policing", and "garden" to a level of ethical superiority that does not exist without its use as a modifier [5]. While the word "community" is often considered to be variable and ambiguous, there is agreement among researchers that any definition should include three basic elements [6]: (1) shared territory, (2) meaningful social interaction, and (3) significant social ties [6]. While communities as networks exist beyond localised scales, the primary concern among academics and the urban planning and design professions is the importance of place to notions of community [3]. This paper looks at communities at the localised neighbourhood scale within an MPC.

\subsection{Social Connectedness}

The interaction between individuals is multifaceted, at the individual, community, and societal levels. In the case of MPCs, the developer consciously constructs an appealing idyllic lifestyle vision encompassing consumer preferences, community ethos, and lifestyle needs, with marketing strategies therefore attracting a specific consumer group. However, this may only account for one layer of what defines a community/neighbourhood. This paper examines the lived experiences and the role in the development of social infrastructure in socially connected communities.

\subsection{Master Planned Community}

MPCs in Australia are usually large, bounded, greenfield developments on city fringes, with significant planning challenges. These challenges include assimilating the development into existing urban landscapes, rolling out suitable support services, and infrastructure (e.g., telecommunications, schools, shops, transport, etc.) [7]. To address these planning issues, MPCs incorporate complementary mixed-use development as part of their multiphase master-planned outcomes [7]. In the Australian context, MPCs are the most capital-intensive type of modern planned private housing estate, integrating different levels of physical and social infrastructure [8]; they are designed to have an individual look, differentiating the MPC as a unique community distinctive from neighbouring residential areas, and thereby creating appeal to a market segment seeking such a community [9]. It has been suggested that MPCs seem to meet a real need in the market for community [3].

The strategic intention of an MPC is strengthened through place-making approaches and a "community compact" [2]. These are designed to facilitate social interaction, foster a collective identity/sentiment, and encourage the development of relational community, thereby building links/bonds, trust, and shared values between residents [7]. The community compact seeks to create immediate familiarity in order to develop "rapid" trust between residents, and between the developer and residents, through establishing homogeneity of values, aspirations, and lifestyles [2]. This immediate familiarity is in contrast to the usual habitual familiarity established over time within neighbourhoods or estates. The MPC community compact and place-making approaches are often complemented with community development programs designed to tie the developer and residents to the MPC vision and establish a localised practice of "community" with a social attachment to place [8].

Planners/developers' community development programs often initiate community sanctioning activities such as community events, newsletters, and a designated website to establish and kindle the community ethos [10]. MPC residents also initiate activities that serve to legitimise the community ethos, the common social code, and estate conventions 
within an amiable setting [2]. It is through the community compact and community activities that residents' expectations are set for behaviour that aligns with belonging to a great community [10].

While MPCs are usually defined as geographically bounded sites [3], they are designed to be socially and community bounded spaces, with developing a strong, place-based sense of community as the primary goal. The effectiveness of the social space is critical to developing community in the MPC $[2,11]$. Social space provides residents with the opportunity for regular and spontaneous face-to-face interactions in their everyday living, thereby enabling communal/neighbourhood connection and community development [12]. This is achieved through a pedestrian-friendly environment of wide footpaths with walkable destinations from mixed-use development (e.g., shops, bars, eating places), pocket parks, and sporting facilities freely and easily available to the community [13]. An MPC with such an environment establishes a distinct social identity and provides casual meeting places that are prerequisites to social connectivity and community development [13].

\subsection{Context}

Australia, like many developed nations, has begun to embrace MPC development. MPCs are seen as a viable strategy to address housing shortages in cities and communities across Australia [14]. MPCs have place-making and community-making approaches purposefully designed to target a particular market segment, which promote the concept of community wellbeing and social connectivity.

Research of the lived and dynamic nature of community life in Australian MPCs is underdeveloped [8], and it is not clear how MPCs are experienced by new residents in the early stages of their development. The present study explores the MPC phenomenon through the lived experience of a diverse group of pioneer residents from a growing MPC in Australia. This study seeks to understand the lived experience of moving to a new MPCommunity.

\section{Materials and Methods}

One of the biggest challenges facing communities is attempting to measure outcomes that are changeable and inconsistent. Applying one measure fails to capture the dynamic needs and preferences of the individuals and the community. Therefore, in this research project, both quantitative and qualitative techniques were employed to uncover deeper insights from the residents' lived experiences.

Qualitative research reveals subjective perceptions and meanings of the social reality; however, it does not identify trends or suggest any generalisation of results across populations. This research aimed to unearth phenomenology to provide a deeper understanding by highlighting meaningful responses from residents [15].

Qualitative research is a recognised and rigorous social research method that is used to gain in-depth knowledge and understanding of phenomena, issues, or questions [16]. This method is often used to explore a topic for the first time, and is quite often used in building and environmental research [17].

To explore the lived experiences of residents over time, a larger longitudinal study was designed, employing mixed methods, and collecting quantitative and qualitative data at 9-10-month intervals over a 5-year period commencing in July 2018. The present study focuses on data collected from the first two stages (July 2018 and May 2019), thereby capturing the lived experience of residents in the early stages of community development within the MPCommunity. A single case study was utilised in order to generate an in-depth, multifaceted understanding of this complex real-life context [18]. This study received ethical approval from the Queensland University of Technology's Human Research Ethics Committee (approval number 1600001085). 


\subsection{The Case Study}

The case study site is a developing MPC located approximately $29 \mathrm{~km}$ from an Australian capital city. The MPCommunity was developed by two major Australian residential estate developers. The estate has access to a major highway and a train into the capital city. The developers' aim was to design a community for easy living, with access to local shops and services, green pedestrian connections, wide open spaces, and public transport. The developers' marketing campaign described living at the MPCommunity as being highly desirable in terms of amenities, access to the capital city, and available green space. It is anticipated that the development and delivery of major infrastructure will take around $12-14$ years. It is proposed that the MPCommunity will include approximately 7000 homes of varied housing types upon its completion.

The MPCommunity is fast-selling. When the first package was marketed, a countdown timer for registration was initiated on the MPCommunity's website; there were $\sim 1000$ interested buyers waiting to put their names down. The capacity of 250 buyer registrations was saturated within $45 \mathrm{~s}$. Buyers were invited to visit the site, and the 75 available lots were sold the following weekend.

The real-estate market in the capital city is tight, with buyers often having to wait years to secure land. The MPCommunity's developers tried to make the process of buying fair for everyone. Interested buyers participated in a lotto-style ballot, registered with AUD 1000 , for the right to be part of the event.

\subsection{Procedure}

Over two time periods—a week in each of July 2018 (Time 1) and May 2019 (Time 2) all residents and buyers of the MPCommunity were invited by the researchers to engage in an online forum. Initially, participants created a unique account that enabled them to enter the online site during the "open days".

\subsection{Online Forum}

This study used quantitative and qualitative measures to deliver an engagement approach that taps into the pulse of community feelings and experiences. All residents and buyers of the MPCommunity were invited to participate in both the online survey and the online forum.

Initially, demographic data were collected from participants, and they were invited to complete the Australian Unity Personal Wellbeing Index and Regional Community Wellbeing Survey. These instruments were used as a framework to identify self-perceived wellbeing in Australian adults in domains such as material wellbeing and personal and community relationship wellbeing [19], examining age, income, relationship status, and other factors that affect personal wellbeing. Since 2001, 37 nationally representative surveys have been conducted using these tools, with more than 65,000 Australian adults participating. The Australian Unity Wellbeing Index is a robust and established instrument that gives a "more comprehensive picture of wellbeing for the individual, the community and society" [19] (p.16).

Qualitative data were gathered over a week in each of July 2018 and May 2019 by using an online forum that was moderated by an experienced online forum facilitator. Online forum conversations were gathered, centred on residents' experiences and perceptions of the topics of place, people, and pursuits within the new MPCommunity. Three questions were asked during the forum: (1) Who are you connecting with in your village? (people); (2) Where are you going to in the village and your local area? (place); and (3) what are you doing in your village and surrounding areas? (pursuits). Participants used words to describe their experiences, and could upload photos or videos. Once the participants had given their responses, they joined the group for an online discussion (if they desired). To facilitate participant engagement, the format of the online discussion was similar to popular social media platforms. 


\subsection{Analysis}

Transcripts of online conversations were analysed using a data-driven approach, where data were examined and organised, manually interpreting and identifying emerging themes. Nvivo12 software was used to support our analyses. Strategic decisions, based on the data analysis and interpretations, determined patterns or themes pertaining to commonalities and the range of variation in participants' experiences and perceptions [20]. This process included iterative data reviews and inter-rater agreement (reliability), establishing a nuanced understanding of the data in terms of emerging themes and meaningful categories [20]. The data were manually coded with the emerging key themes of hope and expectations, sense of community, feelings of exclusion, physical and social infrastructure, and developer-initiated community activities. This process captured conceptual categories that are empirically grounded, revealing the lived experiences of the participants [21].

\section{Results}

\subsection{Demographic Characteristics of Participants}

The demographic profiles of the participants are described in Table 1. Of the 154 participants, there were more males than females. Most participants were younger than 45 , married/partnered, not Australian-born, educated to a graduate/postgraduate level, had an income of less than AUD 120,000, and reported their cultural origins as Australian, Indian, or "other".

Table 1. Demographic information.

\begin{tabular}{|c|c|c|c|}
\hline Topic/Area & Category & Participants Time $1 * * *$ & Participants Time $2 * * *$ \\
\hline \multirow{2}{*}{ Gender } & Male & 45 & 42 \\
\hline & Female & 35 & 32 \\
\hline \multirow{4}{*}{ Age } & Younger than 35 & 39 & 33 \\
\hline & Between 35 and 45 & 29 & 33 \\
\hline & Older than 45 & 8 & 5 \\
\hline & Omitted response & 4 & 3 \\
\hline \multirow{4}{*}{$\begin{array}{l}\text { Relationship } \\
\text { status }\end{array}$} & Married/Partnered & 71 & 66 \\
\hline & Single & 6 & 4 \\
\hline & Divorced & 2 & 2 \\
\hline & Omitted response & 1 & 1 \\
\hline \multirow{5}{*}{ Education } & High school & 7 & 10 \\
\hline & Postgraduate & 21 & 24 \\
\hline & Trade/post-secondary & 19 & 14 \\
\hline & University & 31 & 24 \\
\hline & Omitted response & 2 & 2 \\
\hline \multirow{4}{*}{ Income } & More than AUD 140,000 & 13 & 18 \\
\hline & AUD $120,000-140,000$ & 9 & 20 \\
\hline & Less than AUD 120,000 & 44 & 23 \\
\hline & Omitted response & 14 & 13 \\
\hline \multirow{3}{*}{$\begin{array}{l}\text { Born in } \\
\text { Australia }\end{array}$} & Yes & 27 & 26 \\
\hline & No & 53 & 47 \\
\hline & Omitted response & & 1 \\
\hline
\end{tabular}


Table 1. Cont.

\begin{tabular}{|c|c|c|c|}
\hline Topic/Area & Category & Participants Time $1^{* * *}$ & Participants Time $2 * * *$ \\
\hline \multirow{6}{*}{ Culture } & Australian & 27 & 21 \\
\hline & Indian & $\hat{\imath}$ & 20 \\
\hline & Mixed culture* & $\hat{\imath}$ & 7 \\
\hline & Other $* *$ & $\hat{\imath}$ & 24 \\
\hline & Omitted response & & 2 \\
\hline & Total participants & 80 & 74 \\
\hline
\end{tabular}

NB:^ Time 1 did not capture any other culture apart from Australian. ${ }^{*}$ Participants identified with more than one culture, i.e., Australian and Indian. ** "Other" includes Asian, Sri Lankan, Maltese, Italian, Filipino, Vietnamese, Egyptian, African, etc. ${ }^{* * *}$ Times 1 and 2 were 10 months apart.

\subsection{Quantative-Survey Findings}

Analysis revealed differences between Time 1 and Time 2. In particular, participants reported increased satisfaction with safety and security at Time 2 compared to Time 1 ; in contrast, participants reported reduced satisfaction with the sense of being a part of a community (found at Time 2 compared to Time 1) - that is, participants grew more confident over time about safety and security at the MPCommunity, but at the same time felt less connected to the community. In other words, participants reported high internal life satisfaction, which contrasts with possible external social connectedness. At Time 1, residents reported high overall personal satisfaction across most domains. Of note, at Time 1, scores in the domains of personal relationships and overall life satisfaction were very high (88.2 and 82.5, respectively) in comparison to the national average (see Table 2).

Table 2. Survey questions and results at Time 1 and Time 2.

\begin{tabular}{|c|c|c|c|c|}
\hline \multirow{2}{*}{\multicolumn{2}{|c|}{ Question }} & $\begin{array}{l}\text { Average (Mean) } \\
\text { Score } \\
\text { MPCommunity }\end{array}$ & $\begin{array}{l}\text { Average (Mean) } \\
\text { Score } \\
\text { MPCommunity }\end{array}$ & \multirow[t]{2}{*}{$\begin{array}{l}\text { Average (Mean) } \\
\text { Scores } 2018 *\end{array}$} \\
\hline & & Time 1 & Time 2 & \\
\hline 1 & $\begin{array}{c}\text { How satisfied are you with } \\
\text { your life as a whole? }\end{array}$ & 82.5 & 79.6 & 75.9 \\
\hline 2 & $\begin{array}{l}\text { How satisfied are you with } \\
\text { your standard of living? }\end{array}$ & 83.1 & 81.6 & 79.4 \\
\hline 3 & $\begin{array}{c}\text { How satisfied are you with } \\
\text { your health? }\end{array}$ & 78.6 & 76.3 & 73.2 \\
\hline 4 & $\begin{array}{c}\text { How satisfied are you with } \\
\text { what you are achieving in life? }\end{array}$ & 81.4 & 79.5 & 72.6 \\
\hline 5 & $\begin{array}{l}\text { How satisfied are you with } \\
\text { your personal relationships? }\end{array}$ & 88.2 & 84.5 & 78.6 \\
\hline 6 & $\begin{array}{l}\text { How satisfied are you with how } \\
\text { safe you feel? }\end{array}$ & 67.8 & 75.9 & 80.3 \\
\hline 7 & $\begin{array}{l}\text { How satisfied are you with } \\
\text { feeling part of your } \\
\text { community? }\end{array}$ & 78.2 & 70.0 & 72.4 \\
\hline 8 & $\begin{array}{l}\text { How satisfied are you with } \\
\text { your future security? }\end{array}$ & 70.0 & 70.3 & 71.02 \\
\hline 9 & Personal Wellbeing Index (PWI) & 78.87 & 77.2 & 75.5 \\
\hline
\end{tabular}


Furthermore, results revealed decreases in satisfaction in the domains of standard of living, health, life achievements, and general personal wellbeing (PWI) from Time 1 to Time 2 (81.6, 76.3, 79.5, and 77.2, respectively).

Interestingly, when examining participant responses to question 6 regarding safety, at Time 1, the median score was 7; however, over half of the participants scored below 7 (see Figure 1). Therefore, it is plausible to infer that many residents felt dissatisfied with aspects of safety within the MPCommunity.

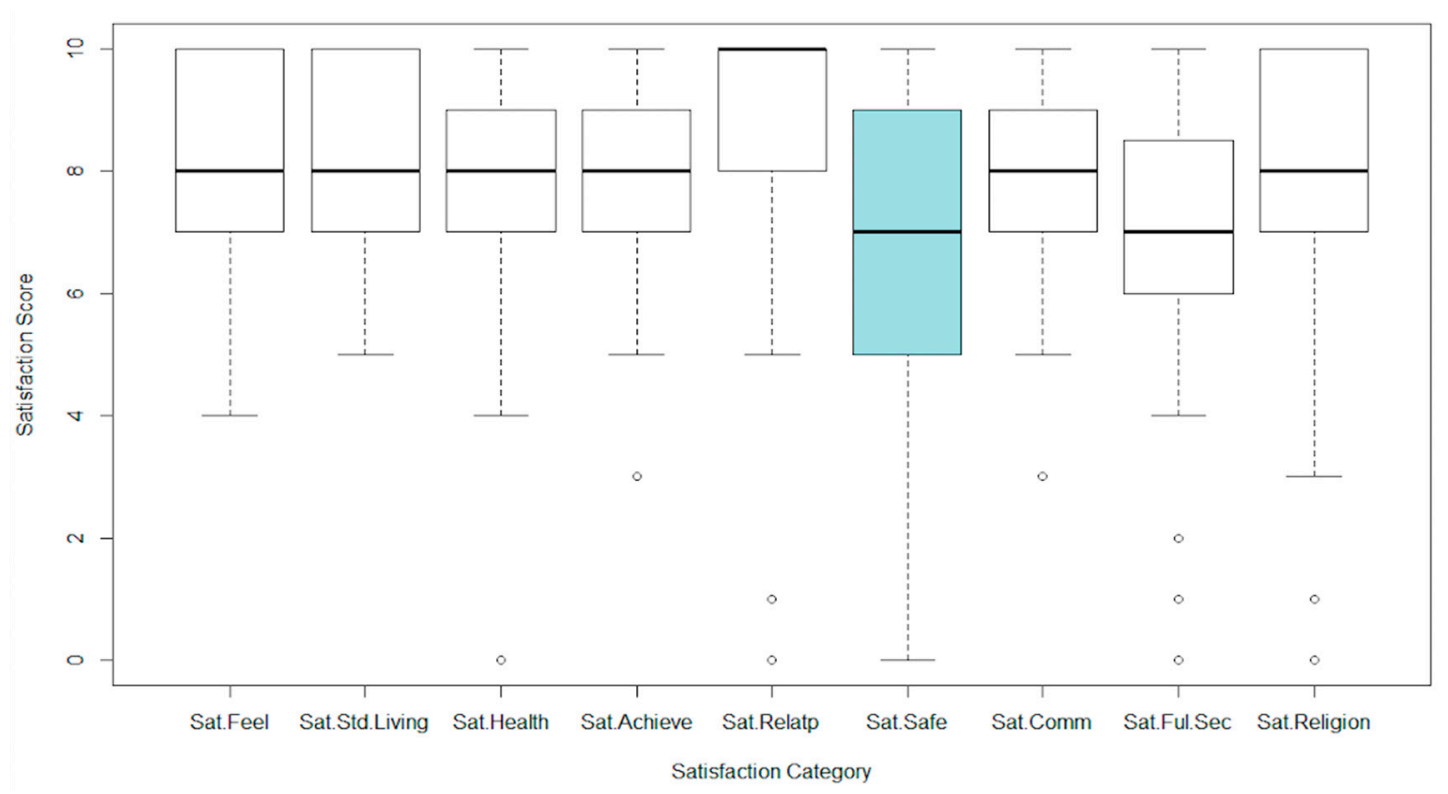

Figure 1. Time 1 (Round 1) satisfaction score distribution.

Further when comparing the same question (Sat.Safe) at Time 2, it was evident that the score range had shrunk, spanning from 4 to 10, which may indicate that those scoring below 7 at Time 1 were more assured over time (see Figure 2). However, as stated above, the scores of this domain remained lower than the national average (see Table 2), which possibly indicates that participants were not fully satisfied with their safety at the MPCommunity. Indeed, there was a great deal of discussion in the qualitative data regarding safety and security.

The distribution analysis for Time 2 evidenced a drastic change in the respondents' sentiments with regard to the level of satisfaction with being part of a community (Sat.Comm). As shown below, the score distribution ranged from 1 to 10 (see Figure 2). When compared with the scores for Time 1, 'Sat.Comm' showed negative growth; therefore, it is possible to argue that MPCommunity respondents were less satisfied with their community than in the previous year.

Analyses of the data using $t$-tests confirmed the sentiments of MPCommunity participants, revealing that the changes across seven of the nine domains from Time 1 to Time 2 did not reach significance, therefore indicating little change in the participants' emotional experiences across time in those domains (see Table 3). However, further substantiating the considerable mean changes reported above for satisfaction with safety (Sat. Safe) and satisfaction with being part of a community (Sat.Comm), the $t$-tests affirmed the changes, with both reaching significance ( $p=0.017$ and $p=0.010$, respectively) from Time 1 to Time 2 . Specifically, satisfaction with safety increased over time. In contrast, satisfaction with being a part of the community declined over time. The qualitative analysis further examines the intersection between safety and the sense of belonging to the community. 


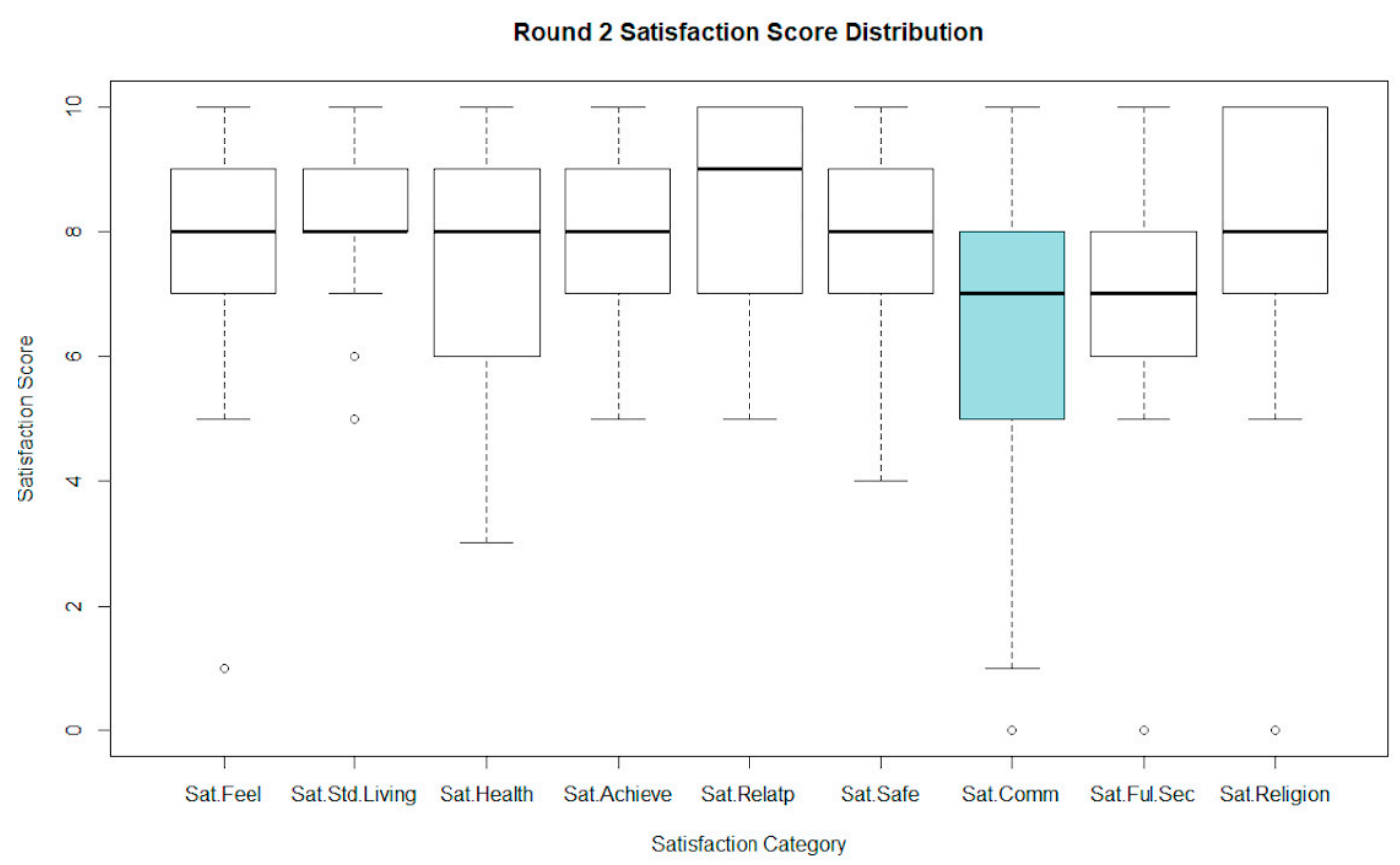

Figure 2. Time 2 satisfaction score distribution.

Table 3. $t$-Test satisfaction results.

\begin{tabular}{cccc}
\hline Satisfaction Domains & $\begin{array}{c}\text { Time 1 } \\
\text { Mean Scores }\end{array}$ & $\begin{array}{c}\text { Time 2 } \\
\text { Mean Scores }\end{array}$ & $\begin{array}{c}t \text {-Test Results } \\
\boldsymbol{p} \text { Values }\end{array}$ \\
\hline Sat.Feel & 8.25 & 7.96 & 0.245 \\
\hline Sat.Std.Living & 8.31 & 8.16 & 0.513 \\
\hline Sat.Health & 7.86 & 7.63 & 0.427 \\
\hline Sat.Achieve & 8.13 & 7.95 & 0.448 \\
\hline Sat.Relatp & 8.82 & 8.45 & 0.187 \\
\hline Sat.Safe & 6.78 & 7.59 & $0.017^{* * *}$ \\
\hline Sat.Comm & 7.83 & 7.00 & $0.010 * * *$ \\
\hline Sat.Fut.Sec & 7.00 & 7.03 & 0.933 \\
\hline Sat.Religion & 7.87 & 8.32 & 0.198 \\
\hline
\end{tabular}

NB: ${ }^{* * *} p \leq 0.05$ indicates statistical differences from Time 1 to Time $2 ; p \geq 0.05$ indicates no statistical differences from Time 1 to Time 2 .

\subsection{Qualitative-Forum Findings}

The forum extended the understanding of the data, and provided further clarity to distinguish differences between Time 1 and Time 2. The robust discussions illustrated the magnitude and earnestness of the connections participants had with the MPCommunity. Interestingly, many participants expressed concern about the consolidation of community within the MPCommunity. However, this could be the logical and even expected progression of community development in the MPCommunity. Importantly, it could be argued that, at Time 1, results revealed the anticipation and excitement-a type of "honeymoon" period-reflecting residents' hopes and expectations, rather than any real sense or experience of community participation. Meanwhile, Time 2, after a period of 10 months, revealed the actual incipient community experiences of residents after the "honeymoon" period of the development, inclusive of the length of time it takes for promised planned infrastructure to materialise. The qualitative results describe this transition under the theme headings discussed below. 


\subsubsection{Theme 1: Hopes and Expectations}

Participants overwhelmingly reported loving living at the MPCommunity and feeling a personal sense of renewal when first becoming residents. Moving into the MPCommunity provided residents with the chance for a new start. Most of the participants felt lucky to have secured a piece of the Australian dream of home ownership, often for the first time. New residents resembled pioneers or honeymooners, with high hopes for their future lives within the MPCommunity. Participants indicated that they expected a high standard of living at the MPCommunity. The findings suggest that participants had bought into the marketing hype around the development, and that their expectations were piqued as a result.

"True, peaceful and quite (sic) life which me and my family looking after ... and I think we can get in the MPCommunity." (R1, Male, 32)

"Moved to [MPCommunity] from Sydney with so much expectations. We are newbies in the community and would love being active in this growing community as I know [MPCommunity] people would listen and would be caring for all our thoughts and views." (R2, Female, 35)

The discussion had a nostalgic feel of desire for a utopian, more traditional neighbourhood, community, and set of values.

"I want to know who my neighbours are so we can look out for each other and create friendships like they do in the old days.". (R2, Female, 30)

"I want neighbours to know one another, to be eating in one another's homes, to see kids playing with each other outside.". (R2, Male, 32)

\subsubsection{Theme 2: Sense of Community}

Despite the decline in terms of satisfaction with being part of a community, participants talked about "loving living at [MPCommunity]" (R2, Female, 59). There was great optimism discussed about the case study community, discussed at Time 1 and Time 2.

"[MPCommunity] has the vibe of a country town with its sense of community while conveniently being close to the CBD. Strangers welcome each other and talk which is really nice and different to where I am moving from." (R1, Male, 28)

"I love the growing community feel (even if this means we still have a long way for dirt flying around, construction on going, constant flyers for blinds and pavers filling up the mailbox)." (R2, Female, 35)

At Time 2, participants identified a number of issues affecting positive community development. They acknowledged that they wanted more frequent and deeper interactions with their neighbours - to create a sense of community/togetherness-" to feel connected and inclusive" (R2, Female, 35).

While they wanted more meaningful and frequent interactions, not all contact was well received.

"[I] look them in the eye and say 'hello, how are you?' They turn their back on you and walk away. I guess some people just don't like to be polite and courteous". (R2, Male, 35)

However, at Time 2, participants recognised the importance of individual responsibility in establishing a sense of community, and working with the developer in making this happen.

"Given that [the developer] is trying so hard to build a community, I'd like to also see people responding to that positively." (R2, Male, 32)

Participants acknowledged the "need to take initiative at least rather than waiting for [an]other to start first" [to] "invite your neighbour to your house" (R2, Male, 45). 


\subsubsection{Theme 3: Feelings of Exclusion}

The forum revealed feelings of exclusion within the general community. These included couples without children, who reported that they felt outside the group norm for most organised community activities.

"We have found that a lot of the activities are aimed at families and children which is great for the kids (unfortunately we have been unable to have kids of our own) ... \{and\}

... feel a little left out of the community feel.". (R2, Female, 35)

Participants without children often had pets, and they indicated that there were a lot of developer-planned activities within the MPCommunity that excluded four-legged family members. Those participants felt that centrally organised community activities that included their pets would be a useful way for them to connect and keep connected to the MPCommunity.

"... we have tried to get involved with some other activities however we were turned away as we had our little dog with us, it would be great for [the developer] to run activities that are inclusive for all as we would love to feel connected to our community". (R2, Female, 35)

The perceived cultural differences within the MPCommunity population also appeared to trigger feelings of exclusion. These cultural differences appeared to discourage social interaction, and resulted in cultural and ethnic-based tensions.

"I also think there is a small amount of racism particularly toward our Indian population. People have made comments that they don't want to attend particular community events or join particular sporting clubs because it's only Indians that attend these events". (R2, Female, 32)

Some participants indicated that there were a number of resident-planned neighbourhood activities in the MPCommunity areas that were culturally based and by invitation only, which resulted in some of the non-invitees feeling excluded.

"Less division from the Indian community in the estate. Shown through their many Indian events over the last couple months ... it feels very segregated". (R2, Female, 26)

\subsubsection{Theme 4: Physical and Social Infrastructure}

After the honeymoon period comes the reality of the day-to-day living experience in an incipient MPC. The findings suggest that participants became impatient with the time it was taking to deliver the promised, master-planned infrastructure. MPCommunity residents often have no choice but to travel long distances for everyday activities such as shopping, work, school, etc. This results in residents spending a lot of time commuting outside of the MPCommunity, which could be spent within the MPCommunity if that physical and social infrastructure was available to them locally.

"grocery is the biggest frustration, I spent around 3 to $4 \mathrm{~h}$ traveling to other suburb weekly to get the basic groceries". (R1, Male, 32)

Residents purchased property in the estate because of the promised and planned infrastructure; however, resident patience started to wane with the extent of commuting required in their daily activity. Most residents use their private cars, as public transportation was found to be non-existent or inconvenient due to frequency or accessibility to transport hubs.

"I'd also like to see the public transport like a bus service to the station and nearby shops as well as an easier pathway to get to the station." (R2, Male, 32)

"Bus service [hasn't] started yet, I know shuttle is in service but it has very limited times and at weekends nothing at all." (R2, Female, 35)

However, while participants voiced their frustration, they remained hopeful that the services and infrastructure would eventually be available. 
"Of course things will only get better." (R2, Female, 40)

"I think It will be much easier getting around once more infrastructure is in place." (R1, Female, 36)

There was considerable discussion around the desirability/need for additional infrastructure, facilities, and services, including:

- A shopping/town centre that includes at least one of the major grocery chains, "good eat out places eg pizza shop hungry jacks and local market" (R2, Male, 36), a post office, library, and a medical centre that includes dental and allied health services.

"It would be much better if we had a town centre asap". (R2, Female, 40)

"I want the Town Centre to be busy, with people walking or riding to the shops and stopping to stay a while and chat to friends and eat in the cafes". (R2, Male, 32)

- Activity rooms "for people to rent out to schedule yoga class, zumba class, etc." (R2, Female, 35)

- Facilities for all residents, especially children and teenagers, including public pool, dance studio, martial arts, gym, etc. Several participants identified the need "to bring teenagers together in the community" (R2, Female, 40).

- An off-leash dog park, because currently the MPCommunity was not seen as a dogfriendly space. Residents with dogs would really appreciate the addition of an offleash dog park within the MPC.

"it would be great to see a park with a dedicated off leash dog zone." (R2, Female, 30)

\subsubsection{Theme 5: Developer-Initiated Community Activities}

Participants recognised the important role the developer plays in getting people to meet one another. The importance of developer-initiated community activities was clearly identified by participants across the two data collections. Such estate-wide communityunifying "get-togethers" organised by the developer at the MPCommunity included a food-truck festival with children's rides, characters, and a DJ; moonlight cinema; treeplanting days followed by sharing pizza together; night markets; a residents' Christmas party; and other resident-only events.

The importance of such events in unifying the diverse residents was highlighted by one participant:

"the turning point was when the movie night happened last summer. It was the mix of cultures and people so warm for each other. We just want our kids to grow up to tolerate and respect each other no matter where their roots are. We could easily picture our family fit in". (R2, Female, 36)

These organised activities also appeared important in "bedding in" the residentsdeveloper relationship. Residents appreciated the developer-initiated community activities and events, and described the relationship between the community and the developer as good.

"Yes. It definitely has that tight knit community feel about it. I think many factors play into this. The developers putting time and effort in creating that type of community through organised events so neighbours can meet and mingle such as 'stage bbq meet ups', just this weekend there was a clean-up Australia day event and pizza night etc. It brings the community together and in turn forms a bond between neighbours. The resident [Facebook page] also fosters community togetherness." (R1, Female, 36)

However, it was also noted that the events:

"... have been good but I find they are 'one off' things and it can be difficult to keep connected." (R1, Female, 36) 


\subsubsection{Theme 6: Safety and Security}

While safety and security scores were less significant at Time 2 than at Time 1, it was a very intense topic of discussion. The desire for a "safe and secure" community was an integral part of participants' utopian reality. Perceived threats to utopian living were factors that threatened the residents' security. The data show that residents are seeking to support their physical and economic security.

\subsection{Physical Security}

Participants were concerned that law and order issues experienced in areas immediately surrounding the MPCommunity could extend into their MPC.

"what is important to me is community safety ... this is important to me as you should feel safe in your home at all times and with the recent events of home invasions and gang meet ups in surrounding suburbs, it won't be long until [MPCommunity] will become a "hangout" suburb" (DP)

Residents said that they were mostly happy with their home environment, but that they did not feel safe in the neighbouring suburbs-posing an immediate challenge, as the promised physical and social infrastructure has not yet been realised, and residents need to go into these surrounding areas to undertake everyday activities such as shopping, entertainment, schools, etc.

"[I] actually feel more unsafe outside of [MPCommunity] ... I'd rather starve than shop at [a particular suburb] these days; it feels SO unsafe to me". (R1, Female, 36)

Many participants want security infrastructure incorporated within the MPCommunity, with some suggesting that "CCTV all around MPCommunity would be nice" (EL), as well as fencing around the estate and secured gates for the entrance. Some participants suggested something similar to "how [another MPC] is designed" (SS).

Participants also discussed the possibility or need for "visible security guards and police patrols" (DCa).

"I would suggest roaming security around the suburb". (DP)

"visibility of police car driving through the estate at random times would make residence feel safe". (M)

However, participants also recognised the importance of connecting with one another to feel safe and secure, as well as establishing a neighbourhood watch group within the estate as a strong safety and security measure.

"Know who your neighbours are. Ensure unsafe activities are reported. Appropriate action from law enforcement agencies. Neighbourhood watch". (PW)

"What is important as a community is to keep in the loop with everyone like a forum sort of thing; the old NABO app for like community events and reporting on security issues. Just things to keep everyone safe in the community". (C)

\subsection{Economic Security}

Of direct consequence to economic security is the lack of promised physical and social infrastructure, including places of employment, shopping, schools, leisure, etc. Participants indicated their disquiet with the time it was taking to deliver on the promised masterplanned infrastructure and services.

Participants were frustrated with having to leave the MPCommunity for nearly every activity outside of their home. Residents of the MPCommunity have no choice in terms of shopping but to travel elsewhere. This puts a lot of time and pressure on residents, because shopping is one of the main chores in daily life. The amount of time spent outside of the MPCommunity is time not spent in activities with family and community within the MPCommunity, reducing the chance to build social networks closer to home. 
"A lot more driving now, an extra 20 min each way to work for me. Further to drive for shops. 13-14 h per week minimum driving. Hopefully that will be less when shops open in [MPCommunity]." (R1, Female, 26)

"If I don't have my car ... I think I can't do anything[sad emoji] stuck at home." (R1, Male, 32)

"Access to good health services and shops are also important to me". (San)

Participants discussed the lack of employment opportunities in the MPCommunity or the local area, resulting in long commutes and less time in the local community.

"I actually resigned from my job ... Moving to [the MPCommunity] definitely had an impact on that decision. I was spending over $1 \mathrm{hr}$ to get to work as I had 2 drop offs in the morning - dropping one child to childcare and the other to school. I am looking for something closer to home now so I have a better work/life balance." (R1, Female, 36)

\section{Discussion}

This research employed a mixed-methods approach to provide the contextual framing necessary to understand the lived experiences of pioneer residents moving into a new MPCommunity. The results demonstrate how the purposeful development of community identity in the early stages of the MPCommunity has not led to satisfactory levels of social infrastructure or social connectedness for the pioneering residents-that is, the physical and social environment, as interpreted by residents against the developers' imagined vision and marketing testimonies, was not entirely satisfactory. Specifically, master-planned infrastructure issues-such as transport, and access to daily activities such as shopping, work, and school-were common and significant points of frustration and dissatisfaction.

The central lifestyle marketing themes for this MPCommunity—such as safety, security, and community infrastructure and connectedness-were captured at Times 1 and 2. In terms of changes from Time 1 to Time 2, Time 1 could be characterised as the "honeymoon" period, when pioneering residents were full of anticipation and expectation for the idyllic lifestyle marketed by the developer. Meanwhile, Time 2 provides an insight into the realities of the day-to-day lived experience, capturing the teething problems as residents became discontented with delays in the rollout of the planned infrastructure. Results revealed a decline in satisfaction over time in terms of the residents' sense of belonging to a community. Nevertheless, most of the participants maintained hope of finding a place where they felt they belonged, reminiscent of their childhood, or an imagined, more secure time representing a more traditional set of family and community values.

While the MPCommunity, as a new development, promises a high standard of housing - which is important for quality of life [22] - the results show that the sense of social connectedness in this new estate is not yet developed. The findings indicate that participants are becoming increasingly impatient with the time that it is taking to deliver promised, master-planned infrastructure, and this appears to have fuelled some of their disquiet in terms of satisfaction with the community. The development of community needs engagement, which requires opportunities and time spent within the community [3]. Currently, in this MPCommunity, this is not possible, as residents need to spend large amounts of time outside the MPCommunity for everyday activities such as shopping and work.

The findings revealed another reason for the decline in satisfaction with being part of the community, which appeared to be related to the cultural heterogeneity of the MPCommunity population. Greater degrees of homogeneity and compatibility have been shown to increase the probability of more intensive relationships that extend beyond a simple exchange of greetings [23]. Similarly, it has been found that ties between non-similar individuals disband more quickly, thus triggering the creation of enclaves within the social environment $[23,24]$. In this instance, the heterogeneity of this MPCommunity appeared to discourage or deter interactions. 
Previous research suggests that there are parts of Australia that experience "multicultural anxiety", founded in safety and security concerns. Many developers strategically position their marketing to promote safe and secure developments, thereby protecting against this anxiety [25]. This MPCommunity has a culturally heterogeneous resident population, as seen in Table 1, who clearly were not looking to escape "multicultural anxiety" - and if they were, their attempts were completely misguided and unsuccessful. However, while not motivated by "multicultural anxiety" this particular resident population was very concerned about safety and security.

\subsection{Sense of Community}

MPC developers know their markets well, and promote more traditional concepts of community [24]. The participants in this study were full of hope and expectation for a "close-knit community" - a community utopia. Most of the participants described being interested in finding a place where they felt they belonged, reminiscent of their childhood, or an imagined, friendlier time representing a more utopian idea of community and community values. Participants reported feeling good about their MPCommunity, but wanted to feel more like a part of the resident community-what has previously been identified as desiring localised neighbourhood [3].

As evidenced in the findings, the community utopia sought by the participants was challenged by their lived experience in the MPCommunity after the "honeymoon" period. Importantly, the participants placed a great deal of value on "friendliness" and "community ethos", which they thought was absent from their MPCommunity, but continued to set as an expectation and desire for its future. Conversely, participants reported they felt lucky to be living in the MPCommunity, and said that they saw the potential for a community utopia, and recognised their own responsibility in making this a reality. Some suggested taking the initiative to be inclusive and engage in more meaningful ways with neighbours, as well as establishing community norms of cooperation, consideration, and kindness to one another; meanwhile, others reminisced about their enjoyment and importance of centrally organised community activities in establishing and strengthening a sense of community. These findings further highlighted the fact that the MPCommunity residents were at different life stages and, therefore, had different needs. Previous research has noted the importance of understanding the different life stages that may determine specific individual demands [3]. Beyond the sense of community connectedness and belonging, participants identified a number of challenges that hindered community utopia-for example, the lack of the promised physical and social infrastructure, which directly impacted organised community activities.

\subsection{Physical and Social Infrastructure}

This MPCommunity was predominantly in the early stages of development-specifically, master-planned physical and social infrastructure (e.g., adequate public transport; pedestrian and bike access to the local train station; shopping/town centre; facilities specifically designed for children, teenagers, pets, etc.) had not yet been realised. Principally, design aspects such as shopping centres, public transport, walkways, bike paths, and parks encourage people out of their homes and into public spaces, where they can meet others engaged in similar activities [12]. Participants with pets and no children reported a sense of exclusion from the community, with the absence of a dog park or organised pet-friendly community events. Many participants saw this lack of infrastructure as inconvenient, and as an impediment to incidental and spontaneous social gatherings or everyday activities. This finding is consistent with previous research that recognises the importance of well-designed physical and social infrastructure in supporting unprompted, natural social connection, facilitating a sense of belonging and trust between residents [3]. Notably, where infrastructure is inadequate, residents are more likely to be lonely, poorly supported, and have limited social agency for change of their circumstances, which are felt by the wider community [3]. 
Moreover, participants with children reported concerns about a lack of child-related areas for activity and play, despite the availability of parks. Parents wanted specific spaces for organised as well as free activities for children, including spaces/rooms for dance, martial arts, a swimming pool, etc. Furthermore, this specific cohort identified the lack of public transport as something that placed significant strain on families, specifically impacting the daily transport needs of the children within the MPCommunity. Having local access to schools through safe walking and bike paths between homes and schools provides children and parents with the opportunity to mix with other local children and adults undertaking the same activity. The critical nature of co-location of schools and homes has been noted in a previous Australian study [3].

The issues with children extended to adolescents. Adolescents are similar to other residents in terms of access to public transport for recreational and entertainment purposes [3], and adolescents can become more isolated from surrounding areas when there are public transport inadequacies. Targeted physical and social infrastructure to link adolescents with activities of interest within MPCs, and provide public transport access to external activities, is considered essential [3]. The participants in this study had strong desires for adolescents to have shared spaces and spend time within the MPCommunity.

A recurring theme and frustration centred on this lack of physical and social infrastructure for everyday activities within the MPCommunity, which consequently required residents to go to neighbouring suburbs for shopping and other services. Participants reported a discomfort within the neighbouring suburbs, leading to distress and disquiet in terms of personal safety and security. Encouragingly, participants expected that this problem will be overcome once the promised infrastructure is fully realised.

It should be noted that participants tabled several solutions to safety and security concerns. These solutions consisted of installing CCTV, security fencing, roving security, or police patrols. However, participants identified the importance of connecting and cooperating with one another in terms of neighbourhood safety and security concerns, including involvement in activities/committees such as neighbourhood watch. Therefore, participants were not simply looking for a "fortress solution"; they recognised the importance of community development, involvement, and engagement in bolstering residents' sense of safety and security.

\subsection{Community Activities}

Beyond the bounds of physical and social infrastructure, participants acknowledged the importance of community groups and events within the MPCommunity. The developer initiated a number of community activities, which were very well received by residents. Participants overwhelmingly spoke positively about developer-organised community events. Participants enjoyed these events, felt that they contributed to the sense of community, and had the desire for more formal activities organised by the developer. In particular, one participant reported that one movie night was a turning point, with the mix of cultures coming together in a warm and welcoming atmosphere. Community activities, facilitated by the developer, have been shown to be an integral component of respondents symbolic conception of the community in an MPC [2]. Organised community activities allow residents to intermingle, which enables social connectivity to develop. Such events also provide residents with the opportunity to build a new identity as part of the MPC and the developer's ideology [2]. Furthermore, these activities provide the opportunity to monitor interactions with other residents in order to determine how well they "fit" with the wider community [2]. While it seems difficult to know how these singular events affect community development-especially when residents come together in an amplified anticipation of celebration [25] - participants reported remembering the events fondly, feeling real connection between residents at the events, and having a real appetite for more such events. The results show that these one-off events further support the development of a community ethos and the growth of community connectedness. 


\subsection{Safety and Security}

There was an improvement in participants' reported levels of satisfaction in terms of the safety and security scores between Time 1 and Time 2 . This may be a reasonably expected progression in the development phases of MPCs-as more homes are built, more people take up residency, thereby creating the feeling of increased safety in numbers. The improvement in satisfaction with safety and security scores at Time 2 was not obvious from the conversations and the survey question results (see Table 2). Furthermore, the level of satisfaction with safety and security remained lower than the national average. However, despite the score improvement, participants were notably vocal in the forum about safety and security issues in the MPCommunity. It could be argued that this reflects unmet expectations derived from marketing promises, as well as a timing issue, evolving from unrealised infrastructure commitments by the developer [26].

The unrealised status of promised physical and social infrastructure also affects economic security, and is an obstruction to authentic feelings of community utopia [27]. Occupational opportunities within the MPCommunity were non-existent. Lack of work within or close to residential communities reduces the opportunity to build social networks closer to home [3]. This structural issue puts community design and work in relation to one another, as the physical and temporal separation of community and care activities from work activities is particularly problematic, and its impact is felt across life-stage groups $[3,28]$.

The most common tool utilised by developers for economic security is "community compact" [13]. Community compact establishes and enforces restrictive covenants (formal) and social norms (informal) designed to establish common social goals of a pecuniary code of beauty for the MPC and the community ethos [7,13]. The MPCommunity has a design review panel (DRP) that approves all components of the house design and construction, landscaping, and building siting. In the MPCommunity, the DRP attracted criticism regarding the consistency of its decisions and the length of time taken to reach a decision. Participants reported that these problems resulted in cost overruns and a lack of confidence and trust in the consistency of the decision-making process. There was also recognised disquiet amongst participants with regard to the state of the public spaces within the MPC. Like other MPCs, the common social norms include highly maintained gardens, cars parked in garages rather than on the road or footpath, and a positive, friendly demeanour to other residents of the MPC $[2,8]$. Participants complained about the state of public spaces and the disruptive effect of residents and visitors parking on roads and footpaths, sometimes blocking thoroughfares.

Participants were critical of the physical state of the community facilities in the MPCommunity, and stressed the importance of these formal and informal covenants. This type of maintenance affects property values, and goes to the heart of economic security [2].

Identity and belonging are strongly linked to home and neighbourhood, with a "sense of home" contributing to security and a sense of order, meaning, continuity, and agency $[29,30]$. As evidenced in the findings, the community utopia sought by the participants was not delivered by their lived experience in the MPC. In general, participants placed a great deal of value on "friendliness" and "community ethos", which was nonexistent. Nevertheless, participants were keen to establish a strong, friendly, cooperative community ethos that was nurtured within the MPCommunity.

The formal and informal covenants within the MPCommunity, while not always adhered to, appeared to offer residents a sense of coherence, community ethos, and social order, as well as a degree of control over the physical and social environment. An important part of this was the community events organised and promoted by the developer, which appeared to go some way toward bringing this community together. These unifying events strengthened residents' sense of security by facilitating social connections between MPCommunity neighbours, creating a strong sense of neighbourhood identity and belonging. Residents were keen to have more of these types of events. Moreover, through these events, as well as the formal and informal covenants and norms, the MPCommunity 
appeared to offer residents a sense of active engagement, rules of belonging, and a code of behaviour, providing an anchor for communal living. Consequently, individual identity and a feeling of predictability were derived, allowing residents to confidently make life plans that strongly contributed to their security.

\section{Conclusions}

Master-planned community estates are promoted, sold, and purchased on the basis of powerful symbols of identity, community, safety, and security [1-3], and it is unclear how this manifests in the lived experience of pioneer residents moving to a new MPC [2,4]. This study addressed this gap and explored-through the lived experiences of residents-the link between how residents felt about the MPCommunity, their wellbeing, and their daily lives. This case study explores an MPC resident population and the evolving community in its early stages of development.

The MPCommunity promises a high standard of housing and infrastructure, which is important for daily life and wellbeing. The social connectedness in this incipient MPC is not yet fully realised in terms of infrastructure and social connections between residents. This case study offers valuable insight into concerns voiced by residents with different perspectives and challenges, living within a new and developing local Australian community. The desire for safety and security are prominent concerns of housing consumers, and enhanced community safety and security increase both the perceived and real value of the community [31]. This is not lost on MPC developers, with safety and security being central to the formation of MPCs, and marketing campaigns playing on prospective residents security fears [27,32]. MPC developers aim to deliver on identity, community, and the inter-related factors of physical and economic security [2,33]. Through capturing participants' lived experiences, it was clear that while the MPCommunity residents have positive feelings toward the estate, there were issues of concern in terms of security. Participants acknowledged that in order to support and strengthen these areas of security, the developer and residents would need to simultaneously work on strategies that addressed the "sense of security" and the "sense of community".

This research addresses significant gaps in previous studies, and contributes to a growing body of knowledge around MPCs and community wellness. One limitation of this research is that results from case studies cannot be generalised to the broader population. However, this study provides "real-life data" of the lived experience of an incipient MPC community. While not definitive, this study offers a level of insight into the lived experiences of community wellness, safety, and security of an emerging heterogeneous MPC. This case study offers valuable insight into how social anxieties associated with a cultural mix of people with different languages and values can overcome the idea of threats to more established ways of life within a local community. By highlighting issues that impact on MPC wellness, safety, and security — especially for heterogeneous resident populations-this research furthers our understanding of the specific factors that make MPCs more desirable environments for existing and future MPC developments.

\subsection{Limitations}

A limitation of this study is that the results of the case study cannot be generalised to a wider population. This case study provides valuable insights into how the cultural combination of people with different languages and values can overcome threats to the more mature lifestyles of local communities. However, for the protection of community health, safety, and life experience, the results of this research cannot be confirmed at present.

\subsection{Future Research}

Based on this exploratory research, future research could develop in a range of theoretical and practical areas. Future theoretical research could focus on social networks in MPCs to explore and test the range of characteristics that explain patterns of inclusion/exclusion and possible structural barriers to communication and cooperation. In addition, future 
research to extend the understanding of community impacts could include social network analysis in order to map changes in the structure of interaction over time, barriers to communication/cooperation, and other relevant topics as they arise over time,

To assist in the future development of sustainable MPCs, additional research is required in order to develop a specific tool or instrument to use with residents, so as to identify issues arising as residents populate new communities.

Author Contributions: Conceptualization, L.B.; methodology, L.B.; formal analysis, L.B. and N.W.; investigation, L.B.; writing-original draft preparation, review, and editing, L.B., C.N. and N.W.; project administration, L.B. All authors have written and reviewed the paper. All authors have read and agreed to the published version of the manuscript.

Funding: Funding for the study was provided by the Developer of the MPCommunity. For confidentiality reasons, the Developers's name has not been included as it would identify the MPC location and potentially the participants.

Institutional Review Board Statement: The study was conducted accordance with the Australian National Health and Medical Research Council guidelines and approved by the Human Ethics Committee at Queensland University of technology (approval code 1600001085, June 2017)

Informed Consent Statement: Informed consent was obtained from all participants involved in the study.

Data Availability Statement: Data are not publicly available due to the potential of identifying individual participants.

Conflicts of Interest: L.B. is an editor for Sustainability. The funders had no role in the design of the study, in the collection, analyses, or interpretation of data, in the writing of the manuscript, or in the decision to publish the results.

\section{References}

1. Terwilliger Center for Housing, Urban Land Institute. Residential Futures: Thought-Provoking Ideas on What's Next for Masterplanned Communities; Urban Land Institute: Washington, DC, USA, 2012.

2. Gwyther, G. Paradise Planned: Community Formation and the Master Planned Estate. Urban Policy Res. 2005, 23, 57-72. [CrossRef]

3. Williams, P.; Pocock, B. Building 'community' for different stages of life: Physical and social infrastructure in master planned communities. Community Work Fam 2010, 13, 71-87. [CrossRef]

4. Bento, F.; Couto, K.C. A behavioral perspective on community resilience during the COVID-19 pandemic: The case of Paraisópolis in São Paulo, Brazil. Sustainability 2021, 13, 1447. [CrossRef]

5. Thompson, J. Beyond the Neighborhood: Community at the Urban Scale. Int. J. Constr. Environ. 2013, 3, 167-179. [CrossRef]

6. Vine, D.; Buys, L.; Aird, R. Conceptions of 'community'among older adults living in high-density urban areas: An Australian case study. Australas. J. Ageing 2013, 33, E1-E6. [CrossRef]

7. Cheshire, L.; Wickes, R.; White, G. New Suburbs in the Making? Locating Master Planned Estates in a Comparative Analysis of Suburbs in South-East Queensland. Urban Policy Res. 2013, 31, 281-299. [CrossRef]

8. McGuirk, P.M.; Dowling, R. Understanding Master-Planned Estates in Australian Cities: A Framework for Research. Urban Policy Res. 2007, 25, 21-38. [CrossRef]

9. Thompson, C. Master-Planned Estates: Privatization, Socio-Spatial Polarization and Community. Geogr. Compass 2013, 7, 85-93. [CrossRef]

10. Walters, P.; Rosenblatt, T. Co-operation or Co-presence? The Comforting Ideal of Community in a Master Planned Estate. Urban Policy Res. 2008, 26, 397-413. [CrossRef]

11. Rosenblatt, T.; Cheshire, L.; Lawrence, G. Social interaction and sense of community in a master planned community. Hous. Theory Soc. 2009, 26, 122-142. [CrossRef]

12. Jacobs, J. The Death and Life of Great American Cities; Modern Library Edition, Random House: New York, NY, USA, 1993.

13. Dowling, R.; Atkinson, R.; McGuirk, P. Privatism, Privatisation and Social Distinction in Master-Planned Residential Estates. Urban Policy Res. 2010, 28, 391-410. [CrossRef]

14. Bajracharya, B.; Donohue, P.; Baker, D. Master Planned Communities and Governance. Available online: http:/ / soac.fbe.unsw. edu.au/2007/SOAC/masterplannedcommunitiesandgovernance.pdf (accessed on 30 September 2021).

15. Lincoln, Y.S.; Guba, E.G. Naturalistic Inquiry; SAGE Publications Inc.: Beverly Hills, CA, USA, 1985.

16. Curry, L.A.; Nembhard, I.N.; Bradley, E.H. Qualitative and mixed methods provide unique contributions to outcomes research. J. Am. Heart Assoc. 2009, 119, 1442-1452. [CrossRef] 
17. Hamza, N.; Greenwood, D. Energy conservation regulations: Impacts on design and procurement of low energy buildings. Build Environ. 2009, 44, 929-936. [CrossRef]

18. Yin, R.K. Applications of Case Study Research; SAGE: Thousand Oaks, CA, USA, 2012.

19. Australian Unity. Evaluating 20 Years of the Australian Unity Wellbeing Index. Available online: https: / / www.australianunity. com.au/wellbeing/what-is-real-wellbeing/20-years-of-wellbeing-research (accessed on 30 September 2021).

20. Flick, U. An Introduction to Qualitative Research; SAGE Publications: London, UK, 2014.

21. Corbin, J.M.; Strauss, A.L. Basics of Qualitative Research; SAGE Publications: London, UK, 2015.

22. Nelson, G.; Sylvestre, J.; Aubry, T.; George, L.; Trainor, J. Housing choice and control, housing quality, and control over professional support as contributors to the subjective quality of life and community adaptation of people with severe mental illness. Adm. Policy Ment. Health Ment. Health Serv. Res. 2006, 34, 89-100. [CrossRef] [PubMed]

23. Gans, H.J. The balanced community: Homogeneity or heterogeneity in residential areas? J. Am. Inst. Plan. 1961, 27, 176-184. [CrossRef]

24. McPherson, M.; Smith-Lovin, L.; Cook, J.M. Birds of a feather: Homophily in social networks. Ann. Rev. Sociol. 2001, 2001 27, 415-444. [CrossRef]

25. Kenna, T.E. Consciously Constructing Exclusivity in the Suburbs? Unpacking a Master Planned Estate Development in Western Sydney. Geogr. Res. 2007, 45, 300-313. [CrossRef]

26. Bauman, Z. Community: Seeking Safety in an Insecure World; John Wiley \& Sons: Hoboken, NJ, USA, 2013.

27. Cheshire, L.; Walters, P.; Wickes, R. Privatisation, Security and Community: How Master Planned Estates are Changing Suburban Australia. Urban Policy Res. 2010, 28, 359-373. [CrossRef]

28. Heid, J.; Urban Land Institute. Greenfield Development without Sprawl: The Role of Planned Communities. Available online: http:/ / europe.uli.org/wp-content/uploads/ULI-Documents/GreenfieldDev.ashx_.pdf (accessed on 30 September 2021).

29. Aidala, A.A.; Sumartojo, E. Why housing? AIDS Behav. 2007, 11, 1-6. [CrossRef] [PubMed]

30. Padgett, D.K. There's no place like (a) home: Ontological security among persons with serious mental illness in the United States. Soc. Sci. Med. 2007, 64, 1925-1936. [CrossRef] [PubMed]

31. Halter, V.R. Rethinking Master-Planned Communities. In Trends and Innovations in Master-Planned Communities; Schmitz, A., Bookout, L.W., Eds.; Urban Land Institute: Washington, DC, USA, 1998; pp. 1-9.

32. Johnson, L.C. Master Planned Estates: Pariah or Panacea? Urban Policy Res. 2010, 28, 375-390. [CrossRef]

33. Costley, D. Master planned communities: Do they offer a solution to urban sprawl or a vehicle for seclusion of the more affluent consumers in Australia? Hous. Theory Soc. 2006, 23, 157-175. [CrossRef] 